\title{
Science Education in the United Kingdom
}

\section{Keith R. F. Elliott}

\section{Introduction}

THE EDUCA T I O N S Y S TEM in the United Kingdom for students beyond the age of sixteen is more specialized than that in many other countries, especially the United States. This is reflected in the degree program, both at undergraduate and graduate levels within the United Kingdom. This paper sets out the background of the pre-university system and how it influences the types of degree program offered within universities in the United Kingdom.

\section{TABLE 1.}

Levels of Study

\begin{tabular}{ll}
\hline Level & Age Range \\
\hline Primary & $4 / 5-11$ \\
\hline Secondary & $11-16$ \\
\hline Tertiary & $16-18$ \\
\hline Further & 18+ Nondegree level \\
\hline Higher & 18+ Degree level \\
\hline
\end{tabular}

\section{Pre-university}

\section{Primary and Secondary}

Children start full-time state schooling during their fifth year, sometimes as early as 4 years 4 months. This is often preceded by nursery or kindergarten. The primary schooling is usually divided into three years in an infant school and four in a junior school, which are normally on the same premises. At the age of 11 most children change school, moving to a secondary school. For the vast majority these 
schools are nonselective, although a number of "grammar" schools still exist where entry is based on academic performance. There is also a significant group of children who move from the public to the private sector at this age.

Full-time education is compulsory until the age of 16. In 1989 the government introduced a National Curriculum for the education of students 5 to 16 years old. This set a general framework for the syllabus in primary and secondary schools within the state sector. The curriculum is not prescriptive but sets a series of levels of achievement and attainment targets for the students. Progress is monitored by SATs (Standard Attainment Tests) taken at 7, 11, and 14. These allow monitoring of both the students and the schools, for which league tables of performance have recently been introduced. Schools within the private sector are not obliged to follow the National Curriculum. Science and mathematics are well represented in the core of the National Curriculum with students expected to spend approximately one-third of their time studying these disciplines.

The final two years of the secondary education are seen as extremely important as it is at this time that students are prepared for the first major set of national examinations-the GCSEs (General Certificate of Secondary Education)-normally taken at 16 . For these examinations the syllabus is more rigidly set within the framework of the National Curriculum by a series of national examination boards. Most students would take about eight subjects in the GCSE examinations. These would include mathematics and science, which may be taken in a number of formats. In the private sector it is still common for students to study and be examined in biology, chemistry and physics as separate subjects. More usually in the public sector students undertake "double award" Science, which includes all three subjects along with an element of earth science. At this level students also study the arts and humanities, including English and a foreign language. After taking the GCSE examinations, students are free to leave full-time education and enter the workforce. The majority however, continue into tertiary education.

\section{Tertiary}


At 16, on entering tertiary education, British students begin to specialize. This may be within the same school as for the secondary education, within the "sixth form," or, increasingly, within a tertiary college. Most students at this stage tend to specialize in one major discipline. There are a number of tertiary qualifications that may be obtained. The most well-known is the GCE (General Certificate of Education) A (Advanced) level. This has been considered the academic "gold standard" of British education and is also taken in many of the countries of the British Commonwealth. Recently a new qualification, the GNVQ (General National Vocational Qualification), has been introduced to encourage more students to continue into tertiary education and to provide a less purely academic, more vocational approach. Both qualifications can lead to entry into university courses although the GCE A-level is still the more recognized.

As with the GCSE examinations, the syllabuses for both the GCE A level and GNVQ examinations are set by a variety of national examination boards. If taking GCE A-levels, students usually take only three subjects in the two years from 16 to 18 . These tend to be closely related, with students specializing in either the sciences or the humanities and not mixing the disciplines. In the case of students intending to continue to science, engineering, medicine, or mathematics degrees the choice is usually three from biology, chemistry, physics, and mathematics (and even further mathematics may be one of the subjects). Unfortunately, science is seen by many students to be "difficult" and there have been problems in recent years in maintaining numbers. The GNVQ, as the name suggests, is a more general qualification. The subject areas are broad, with science (covering all disciplines) being one. For the students specializing in science there is not a total lack of the humanities. Many students also take an additional subject, general studies, which covers a variety of topics.

The completion of tertiary is another exit point from the education system. The United Kingdom has traditionally had a low participation rate post-18. However, recent government initiatives have increased this toward a 30 percent age participation rate. 


\section{The Scottish System}

In Scotland the route through the education system differs somewhat from the rest of the United Kingdom. Primary and secondary educations are very similar except that the examination at 16 is the Scottish Standard Grade, normally taken in eight subjects. Tertiary education remains broader with Higher-Grade examinations being taken at 17 in five subjects, which must include English and mathematics. Students are able to enter university at this stage, although many now continue for a further year to take the optional Certificate of Sixth Year Studies. As a consequence, the university degree courses in Scotland tend to be a year longer than in the rest of the United Kingdom.

\section{Higher Education}

\section{University Admissions}

Entry to all university is via a national application system administered by UCAS (the University and Colleges Admissions Service). Students complete an application form by the Christmas before the September in which they wish to enter university. On this they have six choices, usually taken up by applying for the same, or similar, courses at different universities. At this time most students will not have taken their GCE A-levels (or equivalent) and so offers of places are made by the universities conditionally on the grades obtained. Once a conditional offer has been accepted by the student, there is a contractual obligation on both university and student. Results are announced in August, when places are confirmed. Those students who do not achieve the required grade, or in fact did not get an offer at all in the first round, then enter "clearing" when the final places in courses are filled.

It is still the norm in the United Kingdom for students to study at a university away from their hometown. This is facilitated by the fact that all university education is free (even at Oxford and Cambridge), at least as far as tuition is concerned. In addition, there is a means tested grant 
system and a student loan scheme to provide support for general living expenses.

\section{Undergraduate Degrees}

A consequence of the early specialization is that degree courses in the United Kingdom tend themselves to start with a greater specialization than in many other parts of the world. A student will read a defined subject for example chemistry, physics, engineering (usually specializing in one particular area such as mechanical engineering) or biology, although it is more likely to be one of the subdisciplines such as anatomy, biochemistry, microbiology or physiology. (It should also be noted that medicine, dentistry and veterinary science are undergraduate degrees in the United Kingdom.) The major subject (often called the "Honours" subject) will predominate, probably occupying up to 80 percent of the timetable, from the beginning of the first year.

Traditionally, the undergraduate degree (the B.Sc.) has been of three years duration. As scientific knowledge has expanded there has been a move in recent years toward four-year undergraduate master's programs (which might seem like a contradiction in terms-(e.g., M.Chem. \{chemistry\}, M.Phys. \{physics\}, M.Eng. \{engineering), although not as yet in biology.

Despite increasing numbers in higher education and decreasing resources per student, practical work is still considered extremely important in science education. Practical classes therefore play an important role in undergraduate education from the beginning of the course. In addition, a practical project in the final year is considered an essential component of an "Honours" degree.

\section{Modules and Credit Rating}

Until recently the syllabus of most undergraduate degree courses was quite prescriptive, with the majority of the course being defined as core and being taught as a complete unit. Although not universal, there has been a move toward modular degrees and with it the opportunity to 
credit rate courses. This potentially makes the degree programs more flexible and allows easier transfer of credit between institutions both within the United Kingdom and abroad.

The most common scheme in use is CATS (Credit Accumulation and Transfer Scheme) in which a full year's work is given 120 credits. This has the advantage that there are a number of ways of dividing the year into discrete blocks or units. It also fits neatly with ECTS (European Credit Transfer Scheme) with 60 credits per year. It is hoped that this system will be in place in the near future throughout Europe to aid transnational movement of students. One important aspect of the credit rating within the majority of universities in the United Kingdom is that the credit is based on student load, not contact hours. It would not be unusual for a module to be rated at 10 credits but have only ten to twenty staff contact hours. However, the students would be expected to undertake a considerable amount of independent work, maintaining the concept that students "read" a degree. A figure that is becoming increasingly used is that 1 credit represents approximately ten hours work for the student, with a full year, therefore, being about twelve hundred hours. Clearly this will vary from student to student, depending on ability and motivation, but can be used as a guide.

Although not necessarily related directly to modularization and credit rating, many universities are moving from the traditional three term to a two-semester year. This still does not fit neatly into the calendar, which is constrained by the publication of the GCE A-level results in mid-August and the Christmas and Easter vacations. A period of twelve weeks can be fitted in before Christmas, with the examination period of the first semester immediately after the students return from vacation. However, the second semester is broken by Easter, which is still a major vacation of at least three weeks. Unfortunately, there are variations between universities in the United Kingdom as well as between different countries in Europe and the rest of the world.

\section{"Sandwich" Degrees}

There are close links between universities and industry and research institutes manifested at the undergraduate level as "sandwich" degrees. 
Students spend an additional period, usually a complete year between the penultimate and final years of their university course working outside the university. During the "sandwich" year, the students are usually paid as a technician by the company or institute, which is usually in the United Kingdom but may be anywhere in the world. (My own department over the years has placed students in mainland Europe, the United States, Canada, South America, Africa, and Australia!) This year allows students to obtain firsthand experience of applying the theory and practical skills learn at university to the working environment. At the end of their course, such "sandwich" students are much in demand by potential employers.

\section{Assessment}

Examinations play an important role in assessment of students in the United Kingdom. With the modularization of degree structures there has been a move away from the whole degree classification depending on one set of examinations at the end of the whole program, although "finals" still have an important place. Most degrees will also be classified using assessments based on many different components including reports of practical classes, essays, dissertations, and project reports as well as end of-module examinations. As numbers of students have increased, there has been a move toward simplification of examinations, perhaps using multiple choice questions, but the examination essay is still very common. This can be a problem to students from abroad, particularly if English is not their first language, or if they have not had to write scientific essays in the past.

A confusion and worry to students from outside the United Kingdom is the range of marks that is used in assessing work. Many U.S. students have almost been in despair on finding they have obtained a mark of only 55 percent, which probably represents an average mark in many courses! The reason behind this is that a wide range of marks is traditionally used which represent codes rather than absolute numerical percentages. The normal pass-mark is only 40 percent, which does not mean that a student needs know only 40 percent of the work to pass. At the other extreme, 70 percent is the borderline for the 
highest grade awarded. Table 2 illustrates the grading system used by most universities in the United Kingdom along with approximate equivalences in the United States. It also includes the classifications used when degrees are awarded to students at the end of the course.

\section{TABLE 2.}

\section{Degree Classifications}

\begin{tabular}{llll}
\hline $\begin{array}{l}\text { United Kingdom } \\
\text { Class }\end{array}$ & Mark & USA & \\
\hline I & $70 \%+$ & Grade & Grade Points \\
\hline II(i) & $60-69 \%$ & B/A- & $3.8-4.0$ \\
\hline II(ii) & $50-59 \%$ & C+/B- & $3.0-3.7$ \\
\hline III & $40-49 \%$ & C & $2.0-2.9$ \\
\hline
\end{tabular}

\section{Quality Control and Accreditation}

Quality control within all levels of education, and particularly higher education, is taken very seriously with mechanisms in place to ensure national standards are maintained. All degrees awarded by universities are scrutinized by an external examiner from another university. This is usually a lull professor who takes an active role in both the moderation of standards in individual modules and the final degree classification awarded to students. As well as ensuring standards are maintained across the higher education sector, this also gives an annual review of degrees by an external referee.

In addition to the long-standing external examiner system, which in effect assesses only the end product, the government has introduced assessment of teaching via the HEQC (Higher Education Quality Council). The HEQC is assessing the delivery of courses throughout the higher education sector. Each year a number of disciplines are assessed in every university in the country. The assessment is rigorous and includes the institutional support given to students as well as the quality of the curriculum and its implementation. Results are published allowing prospective students to consider the quality of the education they might receive before making an application. 
Many science degrees are also accredited by professional bodies. For instance, graduates will be able to practice as qualified pharmacists or engineers only it the degree they have been awarded has received full accreditation.

\section{Postgraduate Degrees}

Although slightly beyond the main scope of this paper, it is worth finishing with a comment on postgraduate courses. A high percentage of science students continue to further degrees. These may be one of a number of types. There is the "taught" Master's (M.Sc.), which tends to be a one-year extended specialization in a subdiscipline. There are also a variety of research-based degrees, including the well-recognized Ph.D. (or sometimes, D.Phil.). These tend to be shorter in length than in many other countries, typically only three years, but most of this time is spent on full-time research and not course work. A recent innovation has been the one-year Master's in Research (M.Res.) degree, which is seen as bridging the gap between the three-year undergraduate and Ph.D. degrees. This, combined with the move toward a number of fouryear undergraduate degrees, means that in future the normal time from entering university to finishing a Ph.D. program will be seven years in the United Kingdom.

\section{Conclusion}

It can been seen from the preceding information that the United Kingdom has retained its own specific education system. This involves a much higher degree of specialization at an earlier age than in most other countries and should he borne in mind when international comparisons are made. 